\title{
In-Situ Sensor Response of Copper Oxide Urchin-like Structures
}

\author{
M. O. Orlandi*, A. A. Felix, P. H. Suman and J. A. \\ Varela \\ Interdisciplinary Lab of Electrochemistry and Ceramics \\ IQ-UNESP \\ Araraquara, SP, Brazil \\ orlandi@iq.unesp.br
}

\author{
D. P. Volanti, \\ Department of Chemistry and Environmental Science \\ IBILCE-UNESP \\ São José do Rio Preto, SP, Brazil
}

\begin{abstract}
In this work we report an advanced study of gas sensor performance of copper oxide $(\mathrm{CuO})$ urchin-like structures synthesized by microwave assisted hydrothermal method. Copper oxide in an interesting p-type semiconductor in order to study the mechanisms related to the sensor response of $\mathrm{CuO}$ structures, we developed a special sample holder which enables the simultaneous characterization of materials by $\mathrm{X}$-ray absorption near edge structure (XANES) and electrical measurements. Quantitative XANES analyses showed that the $\mathrm{CuO}$ material can have its surface completely reduced when exposed to $\mathrm{H}_{2}$ in $\mathrm{N}_{2}$ baseline and electrical measurements confirm the abrupt decrease in the material resistance. This superficial reduction is reversible after exposition of sample to a synthetic air atmosphere. Sensor response models for $\mathrm{CuO}$ material based on these findings were proposed.
\end{abstract}

Keywords-Sensors; copper oxide; nanomaterials.

\section{INTRODUCTION}

Nanostructured materials processing have attracted significant interest in recent years and device fabrications based on several self-assembly processes have been available [1-2]. Effectively controlling the size and the morphology of materials at the nanoscale level from a self-assembly process is an interesting subject in both nanoscience and nanotechnology fields [3].

Copper oxide $(\mathrm{CuO})$ is a p-type semiconductor with a band gap of about $1.2 \mathrm{eV}$ exhibiting interesting properties and having several practical applications, such as in solar energy materials, gas sensors, batteries, and as catalyst [4-5]. P-type semiconductors have been investigated as an alternative to ntype semiconductors to enhance the gas-sensing properties of metal semiconductor gas sensor materials due to their high surface reactivity and catalytic properties [6]. Once the materials properties are strongly dependent on their size and shape, it is expected that changing $\mathrm{CuO}$ crystals morphology can improve its use in some of the existing applications. Recently, we have showed the effect of size and shape of copper oxide for gas sensor application [7]. However, the mechanisms responsible for the gas sensing response of this semiconductor are still not fully understood. To help elucidating these mechanisms advanced spectroscopic techniques have been performed concomitantly with electrical measurements under in situ and in operando conditions. The use of X-ray absorption spectroscopy (XAS), like X-ray absorption near edge structure (XANES), can be helpful to observe modifications in the oxidation state of materials under gas-sensing characterization. This type of measurement is very useful due to the knowledge of oxidation state of material when exposed to reactive environments.

In this work, we report an in situ and in operando study using a dispersive XANES technique concomitantly with electrical measurements expecting to correlate the local oxidation state and electrical changes in copper oxide sensing materials under operation conditions.

\section{EXPERIMENTAL PROCEDURE}

All the chemicals used in this work were analytical grade. $\mathrm{CuO}$ crystals were synthesized as follows: $0.5 \mathrm{mmol}$ $\mathrm{Cu}(\mathrm{NO} 3) 2.3 \mathrm{H} 2 \mathrm{O}$ were added to $100 \mathrm{~mL}$ deionized water, and the solution was stirred for 10 minutes. After, $5 \mathrm{~mL}$ of concentrated ammonia solution (NH3 $30 \mathrm{wt} \%$ ) was dripped into the copper solution under stirring for $15 \mathrm{~min}$. The obtained solution was transferred to a $120 \mathrm{~mL}$ autoclave, which was inserted in a microwave system $(2.45 \mathrm{GHz})$, then heated up to $100{ }^{\circ} \mathrm{C}$ and kept at this temperature for 3 minutes. The resulting copper oxide precipitates were collected and washed with deionized water several times. Finally, the powder was dried at $60^{\circ} \mathrm{C}$ in air.

Time-resolved XANES spectra were taken at the $\mathrm{Cu}$ K-edge $(8980 \mathrm{eV})$ in the dispersive X-ray beam line at Brazilian Synchrotron Light Laboratory (LNLS). The range of spectra collected was from 8900 to $9400 \mathrm{eV}$. XANES spectra were collected during cyclic gas exposure to hydrogen, using $\mathrm{N}_{2}$ or synthetic air as the baseline gas, under a constant total flow of $100 \mathrm{sccm}$ (baseline plus analyte gas) using mass flow controllers (MKS). Results presented in this work were obtained at $400{ }^{\circ} \mathrm{C}$. Electrical measurements were performed using a stabilized source-measure unit (Keithley, Model 237) using a constant voltage of $100 \mathrm{mV}$. To perform both measurements at the same time, a special sample holder was developed allowing to obtain the XANES (in transmission mode) and electrical measurements. 
A semi-quantitative analysis of amount of $\mathrm{CuO}, \mathrm{Cu}_{2} \mathrm{O}$ and $\mathrm{Cu}$ in studied samples' was performed by linear combination of the standards patterns and the experimental spectra using Athena software.

\section{RESULTS AND DISCUSSION}

Figure 1a illustrates the time-resolved in situ XANES measurement at the $\mathrm{Cu}$ K-edge of the $\mathrm{CuO}$ nanostructures at 400 ${ }^{\circ} \mathrm{C}$ and Figure $1 \mathrm{~b}$ presents the electrical measurement (gas sensor) obtained at the same experimental conditions, i.e., dry air $(95 \%)$ as the baseline plus $\mathrm{H}_{2}(5 \%)$ as the analyte gas. The spectra in Figure 1a indicate that $\mathrm{CuO}$ is present predominantly in the $\mathrm{Cu}^{2+}$ oxidation state. No change in XANES spectra was observed with the introduction of the analyte gas. The gas sensor response presented in Figure $1 \mathrm{~b}$ is typical of a p-type semiconductor exposed to reducing gases, in which the resistance increases with the analyte exposure [7]. Semiquantitative analysis estimates the relative fraction of different copper species, showing $80 \pm 3 \%$ of $\mathrm{Cu}^{2+}, 20 \pm 10 \%$ of $\mathrm{Cu}^{+}$and no $\mathrm{Cu}^{0}$ present in the $\mathrm{CuO}$ sample, and these values were kept constant during all experiments in synthetic air (with and without the presence of analyte). It is noteworthy that concentration of $\mathrm{Cu}^{+}$observed in the sample comes from the intrinsic defects or the photoreduction caused by X-ray beam, but it is not related to the introduction of analyte gas.

Based on these results and previous reports [7], in an atmosphere containing oxygen, the $\mathrm{H}_{2}$ molecules interact with electronic holes on the $\mathrm{CuO}$ surface, forming $\mathrm{H}^{+}$species above $150{ }^{\circ} \mathrm{C}$, and then react with preadsorbed oxygen species to form hydroxyl groups without any structural/electronic alterations to the solid compound, i.e., the hydrogen molecules induce depletion of holes at the $\mathrm{CuO}$ surface, resulting in increased sensor electrical resistance, as proposed by the ionosorption model $[7,8]$.

To investigate deeper this assumption, another experiment was performed using inert gas $\left(\mathrm{N}_{2}, 95 \%\right)$ as the baseline and then exposing the $\mathrm{CuO}$ sample to $\mathrm{H}_{2}(5 \%)$ as the analyte gas. The results reflected abrupt changes in the XANES spectra (Figure $2 \mathrm{a})$ and in the electrical resistance measurements (Figure 2b) when the $\mathrm{CuO}$ sample was exposed to hydrogen in the absence of oxygen. Right after the injection of hydrogen, the $\mathrm{CuO}$ sensor worked as a typical p-type semiconductor by demonstrating increased electrical resistance, without presenting any changes
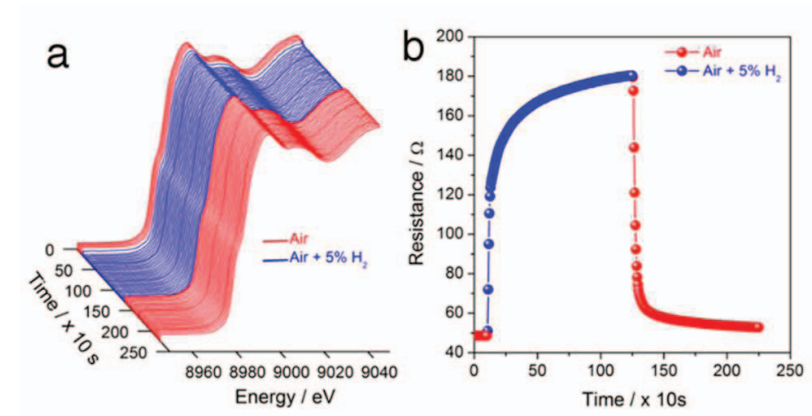

Fig. 1. In situ measurements of $\mathrm{CuO}$ nanostructures at $400{ }^{\circ} \mathrm{C}$ under cyclic exposure to synthetic dry air as the baseline (95\%) plus $\mathrm{H} 2(5 \%)$ as the analyte gas. a) $\mathrm{Cu}$ K-edge time-resolved XANES spectra; b) Sensor resistance change over time.
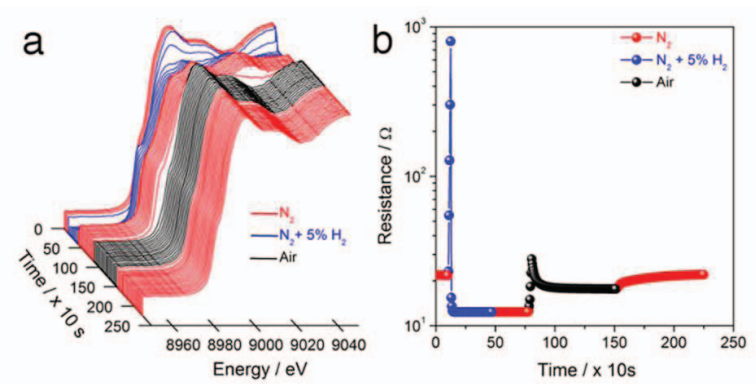

Fig. 2. In situ measurements of $\mathrm{CuO}$ nanostructures at $400{ }^{\circ} \mathrm{C}$ under cyclic exposure to pure dry nitrogen as the baseline (95\%) plus $\mathrm{H} 2(5 \%)$ as the analyte gas. a) $\mathrm{Cu}$ K-edge time-resolved XANES spectra; b)Sensor resistance change over time.

in the XANES spectra. However, few seconds later, the electrical resistance abruptly decreased to very low values, which are typically observed in metals, and significant alterations in the XANES spectra were observed, reflecting changes in the copper oxidation state of the $\mathrm{CuO}$ sample. Copper species quantification indicated the presence of $\mathrm{Cu}^{0}(60 \pm 5 \%)$, $\mathrm{Cu}^{+}(22 \pm 7 \%)$, and $\mathrm{Cu}^{2+}(18 \pm 10 \%)$ species after $250 \mathrm{~s}$ in the presence of hydrogen under a nitrogen atmosphere. These values were significantly altered compared with the initial concentration species $\left[\mathrm{Cu}^{0}(0 \%), \mathrm{Cu}^{+}(20 \pm 10 \%)\right.$, and $\mathrm{Cu}^{2+}$ $(80 \pm 3 \%)]$. This result indicates that adsorbed hydrogen first induces the depletion of holes at the $\mathrm{CuO}$ surface, resulting in increased sensor resistance. However, due to the absence of any oxygen species, the hydrogen reacts with the lattice oxygen, thus inducing the reduction of copper, changing the surface's solid characteristics from those of a semiconductor to those of a metal and consequently increasing sensor conductivity.

In Figure 2a, after $500 \mathrm{~s}$, it is possible to observe that even after hydrogen removal, keeping only the nitrogen baseline, the sample maintained its high reduced copper fractions and low electrical resistance values, which was expected due to the absence of oxygen to induce copper oxidation.

To investigate the oxidation process and the gas sensor properties after oxidation, the sample was exposed to an oxidizing atmosphere by the injection of synthetic dry air to recover the sensor, as shown in black points of Figure 2. At approximately $780 \mathrm{~s}$, the sample was oxidized, returning to its initial concentration of $\mathrm{Cu}^{2+}(80 \pm 3 \%)$ and $\mathrm{Cu}^{+}(20 \pm 10 \%)$ species, and, consequently, the sensor resistance exhibited an abrupt increase resulting from the oxidation process. Finally, at approximately $1500 \mathrm{~s}$, an increase in the electrical resistance was noted again when the nitrogen atmosphere was reintroduced and used until the end of the experiment (2250 s), confirming that the sensor returned to operate as a p-type semiconductor.

Results presented here shows that the reduction/oxidation process in copper oxide is both atmosphere and temperature dependent, which is important for practical applications in sensors, once structural changes of samples in real devices should be avoided. 


\section{ACKNOWLEDGMENT}

We would like to thank Brazilian funding agencies Fapesp and $\mathrm{CNPq}$ for supporting this research. SEM images were provided by LMA-IQ-UNESP. LNLS-CNPEM staff is thankful for the support during XANES experiments (proposal numbers 13710,12584 , and 11845).

\section{REFERENCES}

[1] Cölfen, H.; Mann, S., "Higher-order organization by mesoscale selfassembly and transformation of hybrid nanostructures", Angew. Chem. Int. Ed., v.42, pp. 2350-2365J, 2003.

[2] Y. Wang, B. Liu, S. Xiao, H. Li, L. Wang, D. Cai, D. Wang, Y. Liu, Q. $\mathrm{Li}$ and T. Wang, "High performance and negative temperature coefficient of low temperature hydrogen gas sensors using palladium decorated tungsten oxide", J. Mater. Chem. A, v.3, pp. 1317-1324, 2015.

[3] Lisiecki, I., "Size, shape, and structural control of metallic nanocrystals" The Journal of Physical Chemistry B, v. 109, pp. 12231-12244, 2005.

[4] Chowdhuri, A.; Gupta, V.; Sreenivas, K.; Kumar, R.; Mozumdar, S.; Patanjali, P. K., "Response speed of $\mathrm{SnO} 2$-based $\mathrm{H}_{2} \mathrm{~S}$ gas sensors with CuO nanoparticles". Appl. Phys. Lett., v. 84, pp. 1180-1182, 2004.

[5] Musa, A. O.; Akomolafe, T.; Carter, M. J., "Production of cuprous oxide, a solar cell material, by thermal oxidation and a study of its physical and electrical properties", Sol. Energy Mater. Sol. Cells, v. 51, pp. 305-316, 1998.

[6] Rout, L.; Sen, T. K.; Punniyamurthy, T., "Efficient CuO-nanoparticlecatalyzed C-S cross-coupling of thiols with iodobenzene", Angew. Chem. Int. Ed., v. 46, pp. 5583-5586, 2007.

[7] D. P. Volanti, A. A. Felix, M. O. Orlandi, G. Whitfield, D.-J. Yang, E. Longo, H. L. Tulle and J. A. Varela, "The role of hierarchical morphologies in the superior gas sensing performance of CuO-based chemiresistors", Adv. Funct. Mater., v. 23, pp. 1759, 2013.

[8] M. J. Madou and S. R. Morrison, "Chemical Sensing with Solid State Devices”, Academic Press, New York, 1989. 